\title{
Atlantis
}

Critical Studies in Gender, Culture \& Social Justice

Études critiques sur le genre, la culture, et la justice

\section{Speaking Freely and Freedom of Speech: Why is Black Feminist Thought Left Out of Ontario University Sexual Violence Policies?}

\section{Lindsay Ostridge}

Volume 41, Number 1, 2020

URI: https://id.erudit.org/iderudit/1074016ar

DOI: https://doi.org/10.7202/1074016ar

See table of contents

Publisher(s)

Mount Saint Vincent University

ISSN

1715-0698 (digital)

Explore this journal

Cite this article

Ostridge, L. (2020). Speaking Freely and Freedom of Speech: Why is Black Feminist Thought Left Out of Ontario University Sexual Violence Policies? Atlantis, 41(1), 59-71. https://doi.org/10.7202/1074016ar

\section{Article abstract}

As of January 1, 2017, the Province of Ontario has required all post-secondary institutions to create and maintain a stand-alone sexual assault policy that includes clearly stated complaint and response procedures. This paper brings to bear the influence of Black feminist thought as an analytic tool and politic on the outcomes and omissions of the development of these policies. Analyzing the stand-alone sexual violence policy of the University of Ottawa as a case study, the author conducted a critical discourse analysis with an intersectional lens to determine if intersectionality influenced the policy creation. Findings reveal that policymakers conceptualize gender in a one-dimensional manner, without attention to intersections of sexualized violence with racism and other systems of oppression. A policy with an ill-defined focus on gender can result in a colorblind policy that suggests that the institution should treat all students the same, regardless of systemic disadvantages they might face on the basis of race, class, gender, sexual orientation, or ability. This avoidance can create barriers to reporting. Neoliberalism and the changing university culture are discussed.
All Rights Reserved (c) Lindsay Ostridge, 2020

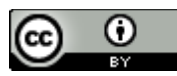

This document is protected by copyright law. Use of the services of Érudit (including reproduction) is subject to its terms and conditions, which can be viewed online.

https://apropos.erudit.org/en/users/policy-on-use/ 


\section{Speaking Freely and Freedom of Speech: Why is Black Feminist Thought Left Out of Ontario University Sexual Violence Policies?}

Lindsay Ostridge is a $\mathrm{PhD}$ candidate at the Institute of Feminist and Gender Studies, University of Ottawa. Her research focuses on analysing current sexual violence prevention campaigns and policies in Canada.

\begin{abstract}
As of January 1, 2017, the Province of Ontario has required all post-secondary institutions to create and maintain a stand-alone sexual assault policy that includes clearly stated complaint and response procedures. This paper brings to bear the influence of Black feminist thought as an analytic tool and politics on the outcomes and omissions of the development of these policies. Analyzing the standalone sexual violence policy of the University of Ottawa as a case study, the author conducted a critical discourse analysis with an intersectional lens to determine if intersectionality influenced the policy creation. Findings reveal that policymakers conceptualize gender in a one-dimensional manner, without attention to intersections of sexualized violence with racism and other systems of oppression. A policy with an ill-defined focus on gender can result in a colorblind policy that suggests that the institution should treat all students the same, regardless of systemic disadvantages they might face on the basis of race, class, gender, sexual orientation, or ability. This avoidance can create barriers to disclosing. Neoliberalism and the changing university culture are discussed.
\end{abstract}

Keywords: campus sexual violence, critical discourse analysis, intersectionality, neoliberalism, sexual violence policy

\section{Introduction}

Violence against women continues to be a problem on Ontario post-secondary campuses. Researchers estimate that four out of five undergraduate women have experienced dating violence (Canadian Federation of Students 2015). Brennan and Taylor-Butts (2008) report that the highest-at-risk group for sexual assault is women between the ages of 15-24. Senn et al. (2014) report that out of 899 undergraduates surveyed, over $50 \%$ of young women experienced one or more forms of sexual violence after 14 years old. Since women are not a homogenous group, many Black feminist writers urge policymakers to use intersectionality as a framework to highlight how the power dynamics of race, gender, class, sexuality, and ableism interact in the everyday lives of women. Understanding how multiple systems of power interact within sexual violence can give the university a greater ability to give meaningful interventions to women on campus (Bourassa, Bendig, Oleson, Ozog, Billan, Owl, \& Ross-Hopley 2017; Wooten 2017).

Despite widespread support for intersectional theory, there has been little change in some Canadian universities' approaches to sexual violence prevention and policy, leaving gaps and oversights that affect students' access to resources. The result can be gender-focused sexual violence policies, which tend to be colour-blind policies that aim to treat all students the same, regardless of any systemic discrimination they may face due to race, class, sexual orientation, and ability within an ever-changing university population (Wooten 2017). So, when prevention campaigns and policies focus on gender only, it negates the many voices of Black feminist writers who think of intersectionality as both a theory and politics (Collins \& Bilge 2016; Crenshaw 1990; Gray \& Pin 2017). The implication of ignoring multiple systems of oppression can be an inadequate 
institutional response to survivors seeking meaningful resources and a safe university campus environment.

The University of Ottawa is a large bilingual researchintensive university. Using this university as a case study, I argue that Black feminist thought is not visible within the discourse of this stand-alone sexual violence policy despite decades of critical thinking. The University of Ottawa's negation of multiple systems of oppression co-occurring can have serious implications for students seeking help and resources. This paper explores the political, representational, and structural problems with a gender-only focused campus sexual violence policy. I suggest that the reason for this negation is due to a preference for neoliberal logic in the university's approach to sexual violence prevention and response, enabling the university to individualize sexual violence and personal safety, increase security measures on campus and sustaining rape myths (Gray \& Pin 2017; Trusolino 2017). This course of action prevents the university from addressing the core issues at the heart of sexual violence, which involve investigating multiple systems of power and control, such as racism and colonialism, alongside gender.

\section{Methods and Methodology}

A case study approach allows for a more detailed, indepth analysis that includes the policy creation process's developmental factors and the context of the campus environment (Flyvbjerg 2011; Stake 2008). The University of Ottawa has a student population of close to 43,000 students $(58 \%$ female, $40 \%$ male, and $3 \%$ undetermined), is located in a prominent mid-size Canadian city, and has been considered within Canadian society as a pillar in the academic and research community since the mid-nineteenth century (The University of Ottawa, n.d.-a). Sitting on un-ceded and un-surrendered Algonquin territory, this university is a member of the U15, a Canadian research-intensive university collective which conducts approximately eight billion dollars' worth of research annually and is one of the largest French-English bilingual universities in the world (The University of Ottawa n.d.-a; U15 n.d.). The University of Ottawa is unique to other Ontario universities. There are 22 publically funded Ontario uni- versities and this university was one of the few that had a stand-alone sexual violence policy before the provincial mandate came into effect (Bill 132 2016; Ontario Universities n.d.). Mattieu and Poisson (2014) report that in 2014, only four Ontario Universities had specific policies to address campus sexual violence, with the University of Ottawa in the process of reviewing their policies at that time. Also, this university does not have a student code of conduct, ensuring that students maintain their right to protest (University of Ottawa 2015). The student population at the University of Ottawa is comprised of $83 \%$ undergraduate students, $11 \%$ master students, and 5\% doctorate students (The University of Ottawa n.d.-a). An independent survey conducted by the Ontario Government (2019) reveals that in the 2017-18 school year, $22 \%$ of students at the University of Ottawa experienced sexual assault and $62.4 \%$ experienced sexual harassment. In these incidents, $87 \%$ of the perpetrators were male and $49.5 \%$ was another student. Only $46 \%$ of survivors disclosed the incident of sexual violence to another person and $9.4 \%$ told an institutional member (Government of Ontario 2019).

Using an intersectional framework, I investigate how the power dynamics of race, class, gender, and ableism may factor into students' everyday lives on campus and how power is replicated in the discourse of the stand-alone sexual violence policy. In my analysis, I employ a feminist critical discourse approach to investigate the University of Ottawa's sexual violence prevention policy. I adopt the understanding that sexual violence is one form of gendered violence, and that law and policy is not equally applied to all persons within a community (Iverson 2016; Wooten 2017). Since the policy under investigation is named "Policy 67b: Prevention of Sexual Violence," I will be using the term "sexual violence" throughout this paper. I approach this document in a "policy as discourse" manner as defined by Bacchi (2000) and with an exploratory and inductive analysis. Investigating how the policymakers represent and create the social problem of sexual violence within the policy's discourse, I pay close attention to power relations.

Within the discourse of policy, I examine how the institution articulates its stance on the issue, setting lim- 
its to the "problem," shaping a solution, and demonstrating what is possible and what is not possible for a survivor who might seek help and resources within the wording of the document (Allan 2008; Iverson 2016, Wooten 2017). Since the policymakers do not exist outside of the campus environment's politics and the societal problem of gender-based violence, I view them as social actors acting within the social constructions of race, class, sexuality, ability, and gender within Canadian society. In this review of the policy's language, I have given additional attention to any taken for granted assumptions, metaphors, and absences within the text to isolate how sexual violence is both constructed and resolved to question further why the policy takes the shape that it does (Allan 2008; Bacchi 1999, 2000; Iverson 2016). After reading the policy numerous times, I identified themes, created links, and gave meaning to the discourse (Allan 2008; Iverson 2016).

\section{The Case Study}

When two high-profile cases of sexual violence involving the University of Ottawa students' came to public attention in 2014, there was a media and public outcry. In response, the University of Ottawa's President, Alan Rock, appointed a task force comprised of faculty, administration, students, and community members to review the problem of harassment and sexual violence and provide solutions to help create a respectful university community. The task force consulted with students, administrators, communitybased experts, and other institutions during their investigation (University of Ottawa 2015). The task force operationalized sexual violence as defined by the Government of Ontario's 2011 Sexual Violence Action Plan, in Changing Attitudes, Changing Lives as:

any violence, physical or psychological, carried out through sexual means or by targeting sexuality. This violence takes different forms, including sexual abuse, sexual assault, rape, incest, childhood sexual abuse and rape during armed conflict. It also includes sexual harassment, stalking, indecent or sexualized exposure, degrading sexual imagery, voyeurism, cyber harassment, trafficking and sexual exploitation. (University of Ottawa, 2015, 7)
While this definition does not mention that the systemic forms of oppression like racism, colonialism, sexism, homophobia, class, or ableism can co-occur in sexual violence, the task force notes that they employed a survivor-centric, values-based, intersectional approach to their analysis of the campus environment as noted in the following statement: "Our task force was also informed by a recognition of the intersectional nature of sexual violence, in which individuals' 'race'/ ethnicity, ability, Indigeneity and socioeconomic status, among other factors, can render them vulnerable on multiple fronts" (University of Ottawa 2015, 7). The task force acknowledges in their report that systems of privilege and oppression could be shaped by "colonialism, imperialism, racism, homophobia, ableism, and patriarchy and interactions occur[ing] with connected forms of power" (University of Ottawa $2015,7)$. The forms of power include "laws, policies, state governments and other political and economic unions, religious institutions and media" (University of Ottawa 2015, 7). However, the task force did not name universities as part of the interconnected forms of power.

As requested by the University of Ottawa's President, the task force created a series of recommendations. The task force recommended that the university create a stand-alone sexual violence policy, independent of older sexual harassment and harassment and discrimination policies. Other recommendations put forth included creating a statement of values which articulates the universities position on respect and equality and committing to providing awareness training to the senior administration, students, and other specified groups (i.e. Bystander Initiatives). The task force also recommended that the university develop an ongoing collaborative relationship with community-based organizations, commit to collecting and making annual metrics on complaints of harassment, sexual violence, and discrimination publically available and provide undergraduate courses exploring the topic of sexual violence. An action team was put in place to ensure that the recommendations were followed (University of Ottawa 2015). These initiatives comprise the university's current sexual violence prevention campaign. 
While these recommendations seem like a positive move to creating a safer learning environment on campus, many stakeholders were outspoken about their lack of confidence in the administration to carry out the recommendations of the task force, having experienced the university acting unilaterally in previous efforts (University of Ottawa 2015). Stakeholders argue that the President was not transparent in how he selected and appointed members of this task force. In addition, the stakeholders expressed concern with the task force's use of sanitized language in official documents. For example, words like "equality" and "respect" are used rather than a more direct and appropriate term, such as "rape culture." These actions to disregard outside input seem to replicate the institution's failure to respond to a 2005-2006 Harassment Working Group's recommendations, made a decade before the formation of this task force. Since the Harassment Working Group's creation was in response to a student-led campaign, the institution's failure to provide more sexual harassment awareness, training, and better policies on campus disappointed many (The University of Ottawa 2015).

In 2016, the University of Ottawa completed the stand-alone sexual violence policy, apparently with the help of students, faculty experts, and community partners (The University of Ottawa 2015). The policy is 16 pages long and includes many definitions, such as "sexual violence," "consent," "sexual assault," "sexual harassment," and the "university community." It includes a statement of values and is survivor-centric. However, I did not find any mention of race, racism, or colonialism within the policy, and appears to me to be a colour-blind sexual violence policy. In other words, I find that the university appears to be framing sexual violence, along with other sexual violence-related terms, in a manner that is ahistorical, decontextualized, individualized, and mostly gender-neutral, by referring to a universal student within the university community. For example, the definition of sexual violence is:

"Sexual violence" means any sexual act or act targeting a person's sexuality, gender identity or gender expression, whether the act is physical or psychological in nature, that is committed, threatened, or attempted against a person with- out the person's consent. It includes sexual assault, sexual harassment, stalking, indecent exposure, voyeurism, non-consensual condom removing (stealthing), and sexual exploitation. For further clarity, sexual assault includes rape. (The University of Ottawa 2016, Section 3.2)

In reading this definition of sexual violence, it appears to me that the university defines sexual violence as something that exists outside of the interlocking power dynamics of gender, race, class, and ableism. Since the policymakers do not name multiple power systems within this definition, I suggest that the university is framing the social problem of sexual violence as an individualized problem. A possible reason for this specific framing could be because the University of Ottawa considers sexual violence to be an outlier-type event that occurs based on the specific characteristics or actions of the survivor or perpetrator (Quinlan 2017). I find that the individualized definition of sexual violence conflicts with the stated purpose of the policy which is to "reaffirm" the university's existing commitment to "a safe and healthy campus for work, for study, and campus community life for all members of the university community and its commitment to provide support to those members of the university community directly affected by sexual violence" (The University of Ottawa 2016; Section 1.1).

While the policymakers do not mention race and ethnicity in the wording of this document, I find they use other words that might reference race, culture, or ethnicity in the policy, words like "marginalized," "discrimination," and "prejudice." For example, the term "marginalized" appears once in the document as part of the institution's values: "The University acknowledges and combats broader social attitudes about gender, sex and sexuality that normalize sexual violence and undermine women and marginalized group's equality" (The University of Ottawa 2016, Section 4.7). I consider the term "marginalized group" to be quite broad, especially since the policymakers do not define what the institution considers a marginalized group within this policy. Furthermore, I find the wording of this portion of the policy suggests that women and marginalized groups are two separate entities that do not exist concurrently, like in the everyday lives 
of women of colour. Also, there is no elaboration on what specific attitudes undermine women and marginalized groups, which is essential since this is the only instance that the words "women" and "marginalized groups" appear in the policy.

The term "discrimination" appears in reference to related policies. The stand-alone sexual violence policy works within a framework of policies, including harassment, discrimination, accessibility, and inclusion (The University of Ottawa Human Rights 2019). At the University of Ottawa, the human rights office manages all complaints of sexual violence, harassment and discrimination, and they report to higher levels of the university administration. The purpose of the stand-alone sexual violence policy is to provide students with transparency, accountability, and reliable and consistent procedures (Shen 2017; The University of Ottawa Human Rights 2019). As stated within the policy, the related policies include the policy on the prevention of harassment and discrimination, the policy on violence prevention, a health and safety policy and a policy on professionalism for the Faculty of Medicine. In terms of which policy to use, the sexual violence policy is only valid when sexual violence occurs. For example, if harassment or discrimination occurs along with sexual violence, the policy advises:

Harassment and/or discrimination: [The sexual harassment policy] and [the policy on harassment and discrimination from students] and [policy on harassment and discrimination for employees] apply to complaints of harassment and/or discrimination that do not involve sexual violence, sexual harassment or workplace sexual harassment. However, only this policy applies if the circumstances of a disclosure or a complaint of sexual violence also encompass harassment and/or discrimination. (The University of Ottawa 2016, Section 6.3)

From this section of the policy, I understand that the stand-alone sexual violence policy is valid if complaints involve sexual violence and the policies within this framework cannot be layered. So, if the university finds that the perpetrator's actions fall within the parameters of the institution's definition of sexual violence, the complainant can file their complaint under the stand-alone sexual violence policy and the response workers will follow this policy in response. However, I find this potentially problematic since there is no antiracist commitment within the stand-alone sexual violence policy. This absence may permit the university to treat the complaint of sexual violence in a decontextualized manner, devoid of consideration for the ongoing racism and colonialism that women of colour may face on campus.

The policy on the prevention of harassment and discrimination (Policy 67a) includes many important factors that create the context in which sexual violence occurs. For example, discrimination can include:

a) a distinction-intentional or unintentional, direct or indirect-because of a person's race, ancestry, ethnic origin, creed, place of origin, colour, citizenship, sex, sexual orientation, gender identity and expression, age, pregnancy, marital status, family status, a record of offences, political affiliation, religious belief, disability or means to accommodate the disability and b) that has the effect of erecting barriers, or creating obligations, disadvantages or situations of unequal treatment that withhold or limit access to privileges, advantages or political, social or economic rights available to other members of society. (The University of Ottawa 2012, para. 23-24)

I find the University of Ottawa's definition of discrimination includes a wider scope of power inequalities that women on campus may experience. I can imagine that by layering Policy $67 \mathrm{a}$ with Policy $67 \mathrm{~b}$ (the standalone sexual violence policy), a more nuanced understanding of how and why sexual violence happens on campus occurs can be developed. Furthermore, other key aspects of harassment and discrimination are essential in providing context to sexual violence on campus, such as systemic discrimination, harassment, poisoned environment, and workplace harassment. For example, the University of British Colombia's Sander School of Business students singing Y.O.U.N.G. rape chant and Pocahontas' chants during frosh week can provide the context and potential motivation for sexual violence (Solinsky 2013). I consider these chants to be examples of a poisonous environment and systemic 
discrimination since women are targeted based on gender, race, and age, resulting in unfair treatment, thus making the environment one which is unsafe to work and study.

Colour-blind policies negate a complainant's ability to have the university consider the historical markers of inequality, like gender and race. These policies falsely assume that everyone is treated equally (Collins 2000; Wooten 2017). Critical race theorists argue that these policies normalize Whiteness and camouflage racism (Collins 2000; Wooten 2017). Colour-blind policies remove the historical markers of inequality and the purposeful degradation of women of colour. Collins (2000) notes that the emerging colour-blind philosophy constitutes a new form of racism within institutions:

A new rhetoric of color-blindness that reproduces social inequalities by treating people the same (Crenshaw, 1997) makes it more difficult to maintain safe spaces at all. Any group that organizes around its own self-interests runs the risk of being labelled "separatist," "essentialist," and anti-democratic. The protracted attack on so-called identity politics works to suppress historically oppressed groups that aim to craft independent political agendas around identities of race, gender, class, and/or sexuality." (121)

Colour-blind policies are detrimental to women of colour's safety and security because they make it diffcult for women of colour to organize within the institution politically and suggest a different narrative to an ill-defined gender-only narrative. Colour-blind policies suppress racialised perspectives by avoiding them (DiAngelo 2011). Racialised women can face unique challenges to disclosing sexual violence, such as cultural shame surrounding discussions about sexuality and sex, meanwhile disclosing sexual violence is very important to positive educational outcomes (Stermac, Horowitz \& Bance 2017).

\section{Top-Down Approaches to Policy Creation}

When policymakers use a top-down approach to policy creation instead of responding to students' needs, the result can be a limited response for surviv- ors. More specifically, a gender-focused approach to a university response can inadvertently set the standard of care based on a universal woman's needs, concealing the interconnecting power dynamics of race, class, gender, and ableism. A universal woman tends to be White, straight, cis-gendered, middle-class, Western, and non-disabled (Gray \& Pin 2017). The outcome of this standard of care is an inadequate response for those needing services that go beyond this universal woman. For example, the policymakers offer little discussion on the complexity of consent and the taken for granted norms about who is afforded the right to consent. The policymakers define consent as:

"Consent" means an active, direct, voluntary, unimpaired, and conscious choice and agreement to engage in sexual activity. These elements of consent must be present, even if alcohol or drugs have been consumed. Consent cannot be given by a person whose judgement is impaired by drugs or alcohol or by other forms of impairment. It is not acceptable for a person who is said to have engaged in sexual violence to use their own consumption of alcohol or drugs as an excuse for their mistaken belief that there was consent. For further clarity, consent: cannot be assumed nor implied; cannot be given by silence or the absence of "no"; cannot be given by an individual who is impaired by alcohol or drugs, or is unconscious; cannot be given by an individual who is asleep; cannot be obtained through threats or coercion; can be revoked at any time; cannot be given if the person who is said to have engaged in sexual violence has abused a position of trust, power or authority; might not be given properly if an individual has a condition that limits his or her verbal or physical means of interaction - in such instances, it is extremely important to determine how consent will be established. (The University of Ottawa 2016, Section 3.2)

From this definition, I interpret consent as an isolated act that is independent of the interconnected power dynamics of gender, race, class, and ableism. I understand that consent is an individual conscious choice, an agreement between two people, that can be given either verbally or physically, and if there is a "condi- 
tion," then the University expects that consent is negotiated between the individuals involved. However, the term "condition" is not elaborated on within the policy and could mean a variety of things. More importantly, this statement might mean little to women in their everyday lives on campus, as this definition does not provide clarity and transparency as the policymakers aim to do. If "condition" refers to a disability, then this is the only time the policymakers mention it in this policy.

Simplistic depictions of consent within a stand-alone sexual violence policy avoids the complexity and the frequency of normalized hegemonic social norms towards who is afforded the ability to consent. For example, Martino (2019) notes that able-bodied people frequently dismiss people with disabilities as not having a right to consent to sexual activity and manage their sexual relationships. In addition to disabled women, women who engage in sex work frequently face ignorant attitudes towards their ability to consent to sex or violence (Martino 2019; Ralston 2019). Since many students engage in sex work as a means to pay for their education, this gap in the policy discourse can make it difficult for a survivor to come forward out of fear that responders might be misinformed or uneducated on the realities of sex workers rights (Josic 2020). The university's avoidance of language that speaks to the complexity of consent within the policy discourse can create more problems for survivors seeking resources than resolving them.

Moreover, I learn little about women's needs by reading the public annual metrics on complaints of harassment, sexual violence, and discrimination on campus. For example, from September 2018-April 2019, the University of Ottawa's Human Rights Office reports 52 complaints of harassment, 13 cases of discrimination based on disability, 9 cases of discrimination based on race, 71 complaints of sexual violence, and 173 students requested information regarding accessibility (The University of Ottawa Human Rights 2019). The report provides no further details about the survivor in terms of race, class, gender, and sexual orientation.

Providing minimal survivor demographic information to the general public appears to be a common practice among post-secondary institutions in Canada. In 2015, Bourassa et al. (2017) investigated 44 English speaking Canadian universities' websites by conducting an environmental scan to determine if institutional on-campus violence policies were available and whether or not each institution had a reporting system that acknowledged the survivors' ethnicity. The authors found that few universities had that system in place. Only six universities recorded the gender and/or ethnicity of the survivor, and this information was not publicly available. The University of British Columbia was the only institution in Canada that addressed violence against Indigenous women and had an intersectional response system (Bourassa et al. 2017).

\section{The Influence of Neoliberalism on Canadian University Campuses}

Many of the gaps and oversights could be due to the ongoing corporatization of Canadian universities (Quinlan 2017). Some argue that the administration has begun to use corporate strategies to organize the university, using top-down approaches such as lean management and performance indicators such as graduation and student employments rates as a focus (Gray \& Pin 2017; Quinlan 2017; The University of Ottawa n.d.-b). These choices are changing the university from a governance structure to a corporate structure where collective bargaining is difficult, strikes occur more often, and the university offers few meaningful resources to survivors (Gray \& Pin 2017; Haiven 2017; Quinlan 2017).

A corporate university comes as a result of reduced government funding (starting in the mid-1990s). The need for funding has created a client/supplier relationship with students, where administrators tend to view students as "revenue-generating agents" (Quinlan 2017). At the University of Ottawa, in 2019, tuition and other fees account for $\$ 453.1$ million out of the total $\$ 1,350$ million in funding sources (The University of Ottawa n.d.-a). Operating grants $(\$ 317.7$ million), research grants, and contracts (\$285.7 million) bring much less money into the university (The University of Ottawa n.d.-a). In order to remain competitive in the marketplace, universities are creating attractive high-fee boutique programs and mass 
marketing these programs to attract and maintain students. Some leading academics argue that the campus administrators may be working to generate a perception of a university community comprising of affluent White students, which, in turn, maintains the university space as a colonial site (Bourassa et al. 2017; Quinlan 2017). Part of these high-fee boutique programs include specialty business programs, where at the University of Ottawa's Telfer School of Management costs between $\$ 28,000$ for the one-year program and $\$ 30,350$ a year for a two-year program depending on the length of the program for domestic students (Telfer School of Management n.d.). This same program is between $\$ 64,000$ and $\$ 68,000$, respectively, for international students.

The University appears to be taking a neoliberal approach to sexual violence by individualizing trauma, preferring to place the responsibility of women's safety in students' hands (Gray \& Pin 2017; Quinlan 2017). According to this logic, sexual violence can be reduced by implementing sexual violence prevention programs that aim to motivate bystanders. One example of such a program is the Bystander Initiative (Gray \& Pin 2017; Quinlan 2017). Gray and Pin (2017) argue that these programs of securitization technologies tend to prey on women's fear without fully engaging in an analysis of the multiple power structures and dynamics co-occurring on campus. Some university administrators prefer these programs because they can give the institution a visible and tangible way to respond to sexual violence (Gray \& Pin 2017; Quinlan 2017). For example, administrators can rationalize the financial cost of implementing the program against a predictive and expected decrease in the rates of sexual violence post-program. However, an increase in reporting rates suggests a safer campus community and an easy campus disclosure system (Gray \& Pin 2017; Quinlan 2017).

\section{Stranger Danger and the Racialised Other}

Gray, Pin, and Cooper (2019) argue that after a public incident of sexual violence, the university administration can create a perception of safety on campus by coopting feminist language within their prevention campaign and sustaining rape myths based on "stranger danger" and the "racialised other." In turn, the University places the focus on women to protect themselves, while reducing the onus on the university to provide meaningful resources and interventions for a safer campus.

Campus officials tend to ignore racism and misogyny within the university community and reinforce these systems of oppression by asking survivors and students to work together to create safety on campus, making individuals responsible for their safety. For example, in 2007, after the Vanier Rape at York University, where two men illegally entered Vanier College dormitory and raped a female student, university administrators and the Toronto Police engaged in messages of securitization (Trusolino 2017). Campus officials created fear among women by telling them to "lock your doors" and "protect yourself" while doing little to prevent male students from engaging in sexual violence (Trusolino 2017). In this case, the university administration capitalised on a nearby low income racialised neighbourhood, emphasizing rape myths such as "stranger danger" and the "racialised other." The focus on racial fear removed the institution's responsibility to provide a safe place for all students to work and study and undermined the collective efforts of autonomous women. Instead, the university increased campus security measures and reified a universal sexual assault victim by avoiding the vital work of investigating the power dynamics of race, class, and gender on campus that are often at the heart of sexual violence.

Furthermore, these messages of the "racialised other" effect racialised male students' ability to live and study on campus without harassment. For example, at the University of Ottawa, media reports brought two separate racial profiling incidents to public attention in 2019. In these incidents, the university's paid security force engaged in racist carding practices, apparently upholding "outdated" policies and procedures (Gergyek 2019). In the first case, security asked a racialised student skateboarding on campus to produce his student I.D. on the spot. When he could not, he was detained by security for police, as if to suggest that his racialised presence was enough for the security personnel to assume an "outsider" status and that he could not be a student at the university (Ahmed 
2012). In a separate incident, a second racialised male student was asked to provide proof of address by the University of Ottawa's paid security force when he used his security card to gain access to his residence. The security personnel did not card a White student who entered the residence only minutes before. Bystanders witnessed this incident, verifying the university's racist security measures (Dutil 2020). In response to ongoing racism on campus, the University of Ottawa created an anti-discrimination committee. Campus officials held two town hall meetings, one with undergraduates and another with graduate students to discuss the prevalence and impact of institutional racism on campus. Since the University of Ottawa is located in downtown Ottawa, close to a shopping centre, multiple hotels, and a men's shelter (Codjoe 2019), some could easily rationalise these security measures due to the physical location of the university.

The state also employs the rape myths of "stranger danger" and the "racialised other" in response to sexual violence. By using a neoliberal logic that views individuals as responsible for their own safety and well-being, the state obscures its ongoing racist and colonialist actions within the legal system, family services, and law enforcement, systems that continue to fail countless women (Maynard 2017; Razack 2016). Police officers tend to treat women who report sexual violence with skepticism and distrust, often with a misunderstanding of the effects of trauma (Johnson 2017). Many officers maintain a very narrow idea of what "real" rape is, preferring to investigate stranger rape over acquaintance rape. The police often act as gatekeepers, providing care and protection to some, while neglecting and abusing others (Razack 2016; Ralston 2019). As contemporary agents of the state, the police enforce systemic oppression based on race, gender, sexual identity, and immigration with the threat of forcing "undesirables" into the prison-industrial complex (Incite! 2016, Jones \& Whynacht 2019; Maynard 2017).

Black feminist thinkers argue for an anti-violent, anticolonialist, anti-racist approach to sexual violence. In order to achieve that, a policy and response system should incorporate a consideration for multiple sys- tems of oppression that occur simultaneously in the everyday lives of women. However, the government and some university policymakers tend to dismiss this approach (Jones \& Whynacht 2019; Maynard 2017; Samaran 2019). Moreover, while many institutions report to involve students and sexual violence experts in the creation of the stand-alone sexual violence policies, as stipulated by Bill 132 (2016), Gray, Pin, and Cooper (2019) argue that some institutions engage in avoidance tactics making it difficult for representatives to attend important consultation meetings. In sum, some administrators fail to consider and incorporate student needs, making student inclusion illusionary. In order to move forward, the university must reconsider this approach.

\section{Conclusion}

In this paper, using a large bilingual research-intensive university's sexual violence policy as a case study, I have demonstrated that the policy is colour-blind and that attention to the multiple intersections of oppression such as gender, race, class, and ableism, while very important, has been negated. Furthermore, I have demonstrated how a colour-blind gender-focused policy can have detrimental implications for many women and men of colour on campus. As the discourse of the policy articulates the university's stance on sexual violence, it appears to me that this university chooses to ignore the interconnected forms of oppression that women face on campus, preferring to use a neoliberal logic to sexual violence prevention and response. I argue that this logic can result in actions such as implementing bystander training and increasing campus security, which sustains rape myths, such as "stranger danger" and the "racialised other." This course of action enables the university to appear to be responding to sexual violence without having to respond to ongoing racism, colonialism, classism, and ableism on campus.

Since rates of disclosure about sexual assault tend to be low at post-secondary institutions, I think it is doubtful that they will improve if the policymakers continue to write policies that are colour-blind and individualistic. University administrators must understand students' experiences to improve the disclosure process for 
survivors and help change the university culture to a truly safe and equitable space for all.

\section{References}

Ahmed, S. 2012. On Being Included Racism and Diversity in Institutional Life. Durham: Duke University Press.

Allan, E. J. 2008. Policy Discourse, Gender and Education: Constructing Women's Status. New York: Routledge.

Bacchi, C. L. 1999. Women, Policy and Politics: The Construction of Policy Problems. Thousand Oaks, CA: Sage.

Bacchi, C. 2000. "Policy as Discourse: What does it mean? Where does it get us?" Studies in the Cultural Politics of Education 21, no. 1, 45-57. https://doi.org/ 10.1080/01596300050005493.

Bill 132. 2016. Sexual Violence and Harassment Action Plan Act (Supporting Survivors and challenging sexual violence and harassment). S.O. 2016 C.2, 1st Session, 41st Legislature: Ontario.

Bourassa, C., Bendig, M., Oleson, E.J., Ozog, A., Billan, J.L., Owl, N., Ross-Hopley, K. 2017. "Campus violence, Indigenous women and the policy void." In Sexual Violence at Canadian Universities: Activism, Institutional Responses, and Strategies for Change edited by E. Quinlan, C. Fogel, A. Quinlan, \& G. Taylor, 4559. Waterloo: Wilfred Laurier University.

Brennan, S. \& Taylor-Butts, A. 2008. Sexual Assault in Canada, 2004 and 2007. Ottawa, ON: Statistics Canada.

Canadian Federation of Students. Spring 2015. Sexual Violence on Campus. Retrieved from: https://cfs-fcee.ca/ wp-content/uploads/2018/10/Sexual-Violence-onCampus.pdf.

Codjoe, E. 2019. Investigation: University of Ottawa June 12, 2019 Protection Services Incident. Retrieved from: https://www.uottawa.ca/president/sites/ www.uottawa.ca.president/files/2019-09-30__final_english_a.pdf 
Collins, P. H. 2000. Black Feminist Thought: Knowledge, Consciousness, and the Politics of Empowerment. New York: Routledge.

Collins, P. H. \& Bilge. S. 2016. Intersectionality. Malden, MA: Polity.

Crenshaw, K. 1990. "Mapping the margins: Intersectionality, identity politics, and violence against women of color." Stan. L. Rev., 43, 1241-1299.

DiAngelo, R. 2011. "White Fragility." International Journal of Critical Pedagogy 3, no. 3: 54-70.

Dutil, C. May 19, 2020. "U of O human rights office report alleges that black student faced racial discrimination in carding incident." The Fulcrum. Retrieved from: https://thefulcrum.ca/news/u-of-ohuman-rights-office-report-alleges-that-black-studentfaced-racial-discrimination-in-carding-incident/.

Flyybjerg, B. 2011. Case Study. In The Sage Handbook of Qualitative Research, 4th Edition edited by N. Denzin and Y. Lincoln, 301-317. California: Sage Publications.

Gergyek, M. October 1, 2019. "Carding of Black U of $\mathrm{O}$ student was racial discrimination, investigation finds." The Fulcrum. Retreived from: https:// thefulcrum.ca/news/carding-of-black-u-of-o-studentwas-racial-discrimination-investigation-finds.

Government of Ontario. 2011. Changing Attitudes, Changing Lives: Ontario's Sexual Violence Action Plan. Queen's Printer for Ontario. Accessed at: http:// www.women.gov.on.ca/owd/docs/svap.pdf.

Government of Ontario. 2019. Summary Report of the Student Voices on Sexual Violence Survey. Retrieved from: https://files.ontario.ca/tcu-summary-reportstudent-voices-on-sexual-violence-survey-en-201903.pdf.

Gray, M., \& Pin, L. 2017. "I would like it if some of our tuition went to providing pepper spray for students: University branding, securitization, and campus sexual assault at a Canadian university." The
Annual Review of Interdisciplinary Justice Research 6, 86-110.

Gray, M., Pin, L. and Cooper, A. 2019. "The illusion of inclusion in York University's Sexual policymaking process." In Dis/Content: Perspectives on Sexual Consent and Sexual Violence edited by KelleyAnne Malinen, 6674. Black Point: Fernwood Publishing.

Haiven, J. 2017. "Rape chant at Saint Mary's University: A convergence of business school ethics, alcohol consumption and varsity sport." In Sexual Violence at Canadian Universities: Activism, Institutional Responses, and Strategies for Change, edited by E. Quinlan, C. Fogel, A. Quinlan, \& G. Taylor, 93-116. Waterloo: Wilfred Laurier University.

Incite! Women of Color Against Violence. 2016. Color of violence: The Incite! Anthology. Cambridge, MA: South End Press.

Iverson, S. V. 2016. "A policy discourse analysis of sexual assault policies in higher education." In The Crisis of Campus Sexual Violence: Critical Perspectives on Prevention and Response edited by S. C. Wooten and R. W. Mitchell, 15-32. New York: Routledge.

Johnson, H. 2017. "Why doesn't she just report it? Apprehensions and contradictions for women who report sexual violence to the police." Canadian Journal of Women and the Law 29, no. 1:36-59.

Jones, E. \& Whynacht, A. 2019. “Tender places: On the intersection of anti-rape activism and prison abolitionism." In Dis/Consent: Perspectives on Sexual Consent and Sexual Violence edited by KelleyAnne Malinen, 142-154. Black Point: Fernwood Publishing.

Josic, A. March 22, 2020. "Sex Work is real for Ryerson Students." The Eyeopener. Retrieved from https://theeyeopener.com/2020/03/sex-work-is-realwork-for-ryerson-students/.

Martino, A., S. 2019. "Power struggles over the sexualities of individuals with intellectual disabilities." In Dis/Consent: Perspectives on Sexual Consent and Sexual Violence edited by KelleyAnne Malinen, 98- 
107. Black Point: Fernwood Publishing.

Maynard, R. 2017. Policing Black Lives: State Violence in Canada from Slavery to the Present. Black Point:

Fernwood Publishing.

Quinlan, E. 2017. "Institutional betrayal and sexual violence in the corporate university." In Sexual violence at Canadian Universities: Activism, Institutional Responses, and Strategies for Change edited by E. Quinlan, C. Fogel, A. Quinlan, \& G. Taylor, 61-75. Waterloo: Wilfred Laurier University Press.

Ralston, M. 2019. "Sex work and the paradox of consent." In Dis/Consent: Perspectives on Sexual Consent and Sexual Violence edited by KelleyAnne Malinen, 108-119. Black Point: Fernwood Publishing.

Razack, S. H. 2016. "Sexualized violence and colonialism: Reflections on the Inquiry into Missing and Murdered Indigenous Women." Canadian Journal of Women \& the Law 28, no. 2: i-viii. https://doi.org/ 10.3138/cjwl.28.2.i.

Samaran, N. 2019. Turn This World Inside Out: The Emergence of Nurturance Culture. Chico, Edinburgh: A.K. Press.

Sawa, T \& Ward, L. February 9, 2015. "U.B.C. sex assault reports out sync with police statistics." CBC News. Retrieved from http://www.cbc.ca/news/canada/ ubc-sex-assault-reports-out-of-sync-with-policestatistics-1.2950264.

Senn, C. Y. Eliasziw, M., Barata, P. C., Thurston, W. E., Newby-Clark, I. R., Radtke, H. L., \& Hobden, K. L. 2014. "Sexual violence in the lives of first-year university women in Canada: No improvements in the 21 st century." B.M.C. Women's Health 14, no. 1: 135.

Shen, A. August 4, 2017. "Universities across Canada implement sexual violence policies: Legislation in three provinces mandate that post-secondary institutions adopt stand-alone sexual violence policies starting this year." University Affairs. Retrieved from: https:// www.universityaffairs.ca/news/news-article/ universities-across-canada-implement-sexual-violencepolicies/.

Solinsky, K. September 18, 2013. "U.B.C. responds to 'Y.O.U.N.G.' rape chant; Aboriginal' Pocahontas' chant emerges." The Abby News. Retrieved from: https://www.abbynews.com/news/ubc-responds-to-yo-u-n-g-rape-chant-aboriginal-pocahontas-chantemerges/.

Stake, R.E. 2008. "Qualitative Case Studies.” In Strategies of Qualitative Inquiry 3rd Edition edited by N.K. Denzin, and Y.S. Lincoln, 119-150. Thousand Oaks, CA: Sage.

Stermac, L., Horowitz, S., Bance, S. 2017. "Sexual coercion on campus: The impact of victimization and disclosure on the educational experiences of Canadian women." In Sexual Violence at Canadian Universities: Activism, Institutional Responses, and Strategies for Change edited by E. Quinlan, C. Fogel, A. Quinlan, \& G. Taylor, 27-44. Waterloo: Wilfred Laurier University.

Telfer School of Management. (n.d.). Tuition Fees. Retrieved from: https://telfer.uottawa.ca/en/mba/ financing/tuition-fees/

The University of Ottawa. 2012. Policy 67a: Prevention of Harassment and Discrimination. Retrieved from: https://www.uottawa.ca/administration-andgovernance/policy-67a-prevention-of-harassment-anddiscrimination.

. 2015. The Report of the Task Force on Respect Force on Respect and Equality: Ending Sexual Violence at the University of Ottawa. Retrieved from: https:// www.uottawa.ca/president/sites/ www.uottawa.ca.president/files/report-of-the-taskforce-on-respect-and-equality.pdf.

. 2016. Policy 67b: Prevention of Sexual Violence. Retrieved from: https://www.uottawa.ca / administration-and-governance/policy-67bprevention-sexual-violence. 
n.d. -a. Institutional Research and Planning.

Retrieved from: https:/www.uottawa.ca/institutionalresearch-planning/resources/facts-figures/quick-facts.

. n.d.-b. Performance Indicators. Retrieved from:

https://www.uottawa.ca/institutional-research-

planning/resources/facts-figures/performance-

indicators.

The University of Ontario Human Rights Office. 2019. Activity Report 2018-2019. Retrieved from:

https://www.uottawa.ca/respect/sites/

www.uottawa.ca.respect/files/activity_report-sept18-

april19-final_eng-v1.pdf.

Trusolino, M. 2017. "It's not about one bad apple." In Sexual Violence at Canadian Universities: Activism,

Institutional Responses, and Strategies for Change edited by E. Quinlan, C. Fogel, A. Quinlan, \& G. Taylor, 7992. Waterloo: Wilfred Laurier University.

U15 Group of Canadian Research Universities. n.d. About Us. Retrieved from: http://u15.ca/about-us.

Wooten, S. C. 2017. "Revealing a hidden curriculum of black women's erasure in sexual violence prevention policy." Gender and Education 29, no. 3, 405-417. doi:10.1080/09540253.2016.1225012. 